\title{
GERMINAÇÃO, CRESCIMETO INICIAL E NODULAÇÃO EM VIVEIRO DE SABOARANA (Swartzia laevicarpa AMSHOFF)
}

\author{
Francisco Wesen MOREIRA ${ }^{1}$, Fátima Maria de Souza MOREIRA ${ }^{2}$, Marlene \\ Freitas da SILVA
}

RESUMO - Swartzia laevicarpa Amshoff ("Saboarana") é uma leguminosa cuja capacidade de se associar simbioticamente a bactérias fixadoras de nitrogênio foi recentemente descoberta. A madeira pode ser explorada econômicamente para: marcenaria de luxo, carpintaria e construção em geral, além disso é uma espécie bastante frequente em rios de água preta, e tem boa disponibilidade de sementes. Características da germinação natural de suas sementes e do crescimento inicial e nodulação em 5 substratos no viveiro foram pesquisadas. As sementes têm polimorfismo acentuado, poliembrionia e apresentam alta porcentagem (94\%) de germinação hipogeal num período de 18-43 dias após a semeadura (realizado 8 dias após a coleta). Todos os parâmetros de crescimento avaliados como: altura da planta, diâmetro do colo e peso da parte aérea fresca e seca foram maiores nos substratos de baixa fertilidade - Areia com adubo inoculada com rizóbio, convencional (mistura argila e areia 3:2) e terriço de floresta sem adubo. A nodulação foi maior no substrato convencional. Nos substratos de maior fertilidade - solo de várzea e terriço de floresta com adubo - o crescimento e a nodulação foram significativamentes menores. Estes resultados indicam que a "Saboarana" é uma espécie adaptada a condições de baixa fertilidade.

Palavras chaves: sementes, Leguminosae, mudas, rizóbio.

Germination, Initial Growth and Nursery Nodulation of Saboarana (Swartzia laevicarpa Amshoff)

ABSTRACT - This paper reports characteristics of seeds and seedlings of saboarana (Swartzia laevicarpa Amshoff), a nitrogen fixing tree species native to Amazonian forests in the blackwater floodplains that produces good quality commercial timber and abundant seeds. The seeds present polimorphism, polyembryony and hypogeal germination. Seeds planted eight days after harvesting takes 18 to 43 days to germinate. The average germination percentage was $94 \%$. Seedling growth, measured as height, diameter, fresh and dry weights, was observed under nursery conditions using five different substrates. Seedling growth was better in the substrates composed of fertilized inoculated sand, a 3:2 claysand mix and in the litter layer of forest soil than in the other substrates tested. Nodulation was better in the clay-sand mix. In the other (high fertility) substrates, poor nodulation and seedling growth was verified. Thus, these results indicate that saboarana is a species adapted to low-fertility conditions.

Key words: seeds, Leguminosae, seedlings, rhizobia.

\section{INTRODUÇÃO}

A familia Leguminosae é uma das maiores dentre as dicotiledôneas, abrigando cerca de 650 gêneros que reunem mais de 18.000 espécies, distribuídas em todo o mundo especialmente nas regiões tropicais e sub-tropicais (POLHILL et àl, 1981). Muitas leguminosas com potencial econômico são encontradas na Amazônia brasileira, dentre elas a

1 Coordenação de Pesquisas em Ciências Agronômicas (CPCA), Instituto Nacional de Pesquisas da Amazônia (INPA), Alameda Cosme Ferreira, 1756, Caixa Postal 478, Manaus, AM, Brasil, CEP 69083-000

2 Departamento de Ciência do Solo, Universidade Federal de Lavras, Caixa Postal 37, 37200-000, Lavras, MG.

3 Centro de Ensino e Pesquisas Florestais (CEPEF), Universidade de Tecnologia da Amazônia (UTAM), Av. Darcy Vargas, 1200, Parque Dez, Manaus, AM. 
"Saboarana" Swartzia laevicarpa Amshoff.

Várias espécies da família Leguminosae apresentam uma importante associação simbiótica com bactérias fixadoras de nitrogênio dos gêneros Rhizobium, Bradyrhizobium, Azorhizobium ou Sinorhizobium. Estas bactérias formam estruturas denominadas nódulos nas raízes ou excepcionalmente no caule de algumas espécies.

Swartzia laevicarpa Amshoff, conhecida no Brasil como Saboarana ou Saboarana branca e na Guiana colno Itikiburaballi, é uma espécie com nódulos radiculares (MAGALHÃES, 1989; MOREIRA et al., 1992) pertencente a subfamilia Papilionoideae, que ocorre também no Suriname, Guiana, Venezuela e Colômbia. No Brasil tem grande dispersão principalmente no Estado do Amazonas, sendo menos frequente no Pará. Segundo DUCKE (1949) ela pode ser encontrada em solos arenosos, nas matas de igapó e rios de água preta, sendo uma das espécies mais frequentes do gênero. Com relação a sua utilização econômica, a "Saboarana" pode ser explorada para marcenaria de luxo, carpintaria e construção em geral (LOUREIRO et al., 1979).

No trabalho de LOUREIRO \& RODRIGUES (1975) sobre esta espécie, podem ser encontradas as características botânicas, fenologia, características gerais e descrições microscópica e macroscópica da madeira.

Este estudo teve por objetivo fornecer dados básicos para utilização silvicultural da "Saboarana", como: coleta e germinação de sementes, repicagem, crescimento e nodulação de mudas em diferentes substratos no viveiro.

\section{MATERIAL E MÉTODOS}

As Sementes de "Saboarana" foram coletadas no período de 24 a 28 de maio de 1986, de matrizes submersas acima do DAP (Diâmetro na Altura do Peito) no Arquipélago de Anavilhanas. $\mathrm{O}$ material botânico dessas matrizes foi encaminhado ao Departamento de Botânica do INPA para identificação da espécie e registro no herbário sob o número INPA 138.784 .

Oito dias após a coleta, no laboratório, as sementes foram retiradas dos frutos e submetidas aos seguintes testes de caracterização do lote: Peso de 1.000 sementes e sua relaçao com o peso dos frutos (porcentagem). Em seguida, foi efetuado o teste de germinaçao em caixa germinadora de $60 \mathrm{~cm} \times 20 \mathrm{~cm}$, com areia lavada. Esta caixa foi colocada em casa de vegetação com cobertura de telhas de plástico transparente. Não foi realizado qualquer tratamento para acelerar a germinação destas sementes, uma vez que elas não apresentam tegumento duro. As sementes foram distribuidas em quatro lotes com vinte e cinco sementes cada, a profundidade de 7 $\mathrm{cm}$. Após a semeadura, foram feitas observações (diárias) de número de sementes germinadas por lote. Considerou-se como sementes germinadas aquelas que tiverem seu tegumento rompido, com posterior 
emissão do caulículo. Durante a condução do experimento, a umidade foi assegurada através de regas periódicas. Acompanhou-se a germinação até que não houvessem mais sementes com possibilidade de germinar. Amostras de plântulas em diferentes fases de desenvolvimento foram conservadas em álcool $(70 \%)$ com gotas de glicerina, e encaminhadas ao Departamento de Botânica para incorporação no herbário.

Aos trinta e quatro dias após a semeadura, 75 plântulas foram repicadas e distribuídas casualmente em 3 blocos de 5 plântulas (uma por saco), em cada um dos seguintes substratos:

1) Areia lavada, procedente da Estrada Am $010 \mathrm{Km} \mathrm{26}$, adubada (por saco) com $3 \mathrm{ml}$ de $\mathrm{Ca} \mathrm{SO}_{4}(1 \mathrm{M}), 4 \mathrm{ml}$ de $\mathrm{K}_{2} \mathrm{SO}_{4}(1 \mathrm{M}), 2 \mathrm{ml}$ de $\mathrm{Na}_{2} \mathrm{HPO}_{4}$ (1M), $4 \mathrm{ml}$ de $\mathrm{Mg} \mathrm{SO}_{4}(1 \mathrm{M}), 1 \mathrm{ml}$ de solução de micronutrientes e inoculado com $10 \mathrm{ml}$ (por saco) de um coquetel de 100 estirpes de rizóbio isoladas de espécies florestais; 2) Solo de várzea (procedente do Rio Ariaú, margem esquerda do rio Solimões); 3 ) Convencional - Mistura de argila com areia na proporção de $3: 2$ procedentes da Reserva Florestal Ducke; 4) Terriço da floresta (procedente das Matas de Reserva Florestal Ducke); 5) Terriço de floresta com adubação mineral (3 $\mathrm{g}$ de calcário dolomílico, $0,2 \mathrm{~g}$ de superfosfato simples, $0,2 \mathrm{~g}$ de fosfato de rocha Araxá, $4 \mathrm{ml}$ de $\mathrm{k}_{2} \mathrm{SO}_{4}(1 \mathrm{M})$ e $1 \mathrm{ml}$ de sol. de micronutrientes, por saco). Nitrogênio mineral não foi adicionado aos substratos para evitar inibição da nodulação.

Foram utilizados sacos de polietileneo de dimensões $24 \times 18 \mathrm{~cm}$, com $3 \mathrm{~kg}$ de substrato. Os substratos $2,3,4$ e 5 nao foram inoculados para que se pudesse verificar o potencial das estirpes nativas desses solos.

Após a repicagem, as mudas foram colocadas em viveiro com cobertura de sombrite (50\%) e irrigadas diariamente. Durante 4 meses, foram feitas medidas mensais de altura das mudas no viveiro, considerando-se para esta medida a distância entre o colo e a gema apical.

Quatro meses após a repicagem, colheram-se 5 plantas de cada substrato para determinações de altura da planta, diâmetro do colo, pesos da parte aérea fresca e seca, pesos da raiz fresca e seca, número e peso dos nódulos secos.

\section{RESULTADOS E DISCUSSÃO}

Vários indivíduos de "Saboarana" foram localizados no Arquipélago de Anavilhanas no período de 24 a 28 de maio de 1986. Todas as árvores possuiam frutificação abundante no mesmo estágio de maturação dos frutos. Cerca de 500 frutos foram coletados de 3 matrizes. Estes frutos continham de 1 até 3 sementes. As sementes de Saboarana têm um polimorfismo acentuado e após germinação, foi observado que podem ser poliembriônicas, apresentando até 3 embriões. Em um total de 100 sementes, verificou-se a incidência de 3 sementes com 2 embriões e uma semente com 3 embriões.

No lote coletado o peso de 1.000 sementes equivaleu a 10.710 gramas, correspondendo a $37,36 \%$ do peso to- 
tal dos frutos.

$O$ teste de germinação revelou que a "Saboarana" tem germinação hipogeal como pode ser observado na Fig.1. A germinação das sementes iniciou 18 dias após a semeadura e atingiu o climax após 25 dias (Fig.2). Apenas 6 sementes não germinaram e apodreceram durante o teste de germinação. Estes resultados indicam que sementes de "Saboarana", neste período ( 8 dias após a coleta no mês de maio), apresentam boa porcentagem de germinação $(94 \%)$ e, portanto, alta viabilidade.

A produção de mudas de boa qualidade é um dos mais importantes problemas nos trabalhos de reflorestamento. A qualidade das mudas é verificada comumente em termos práticos através dos seguintes parâmetros morfológicos: altura da parte aérea, diâmetro do colo, peso da parte aérea, relação entre parte aérea
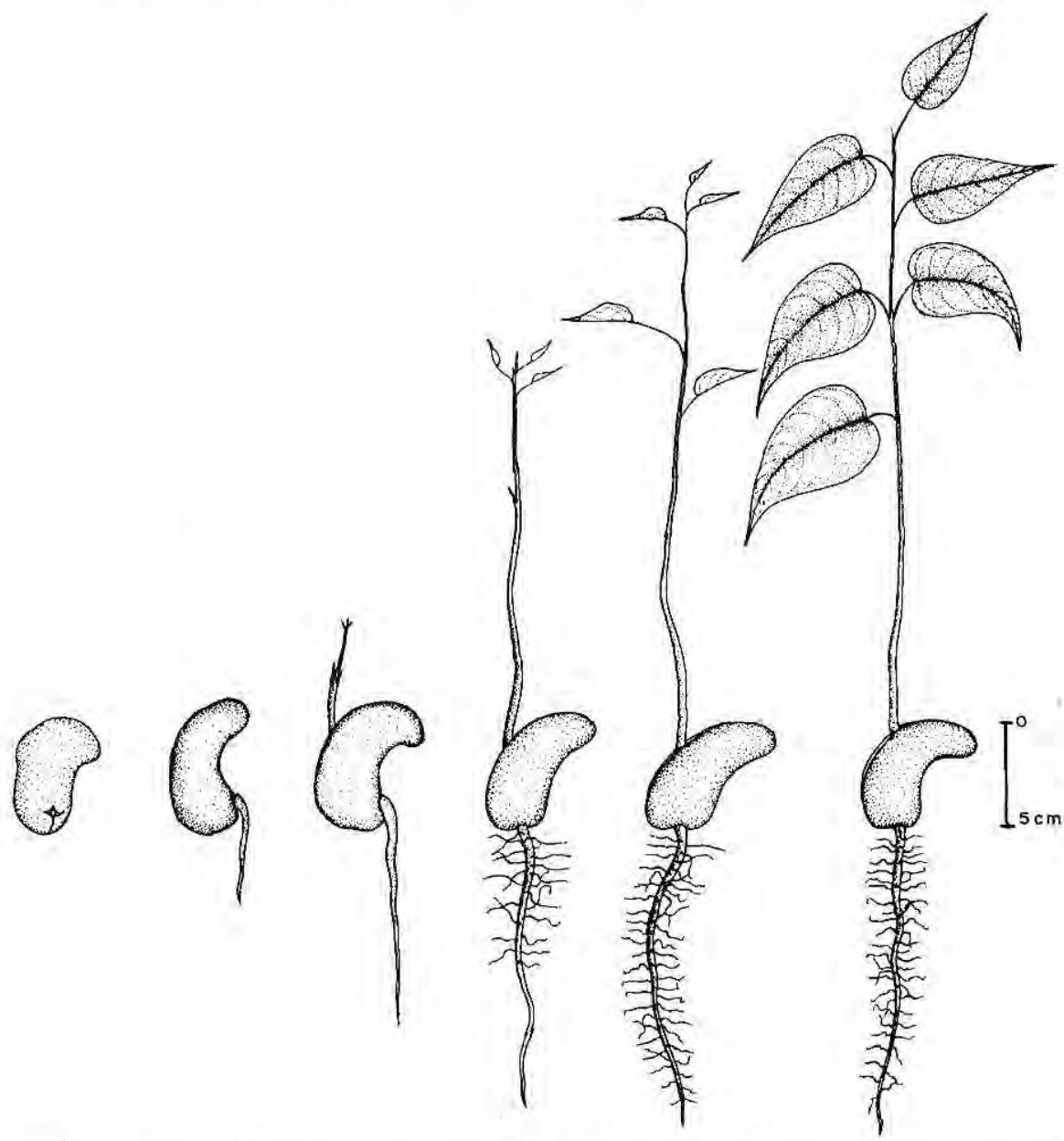

Figura 1: Swartzia laevicarpa Amshoff (Saboarana): sequência de diferentes estádios de plântulas. 


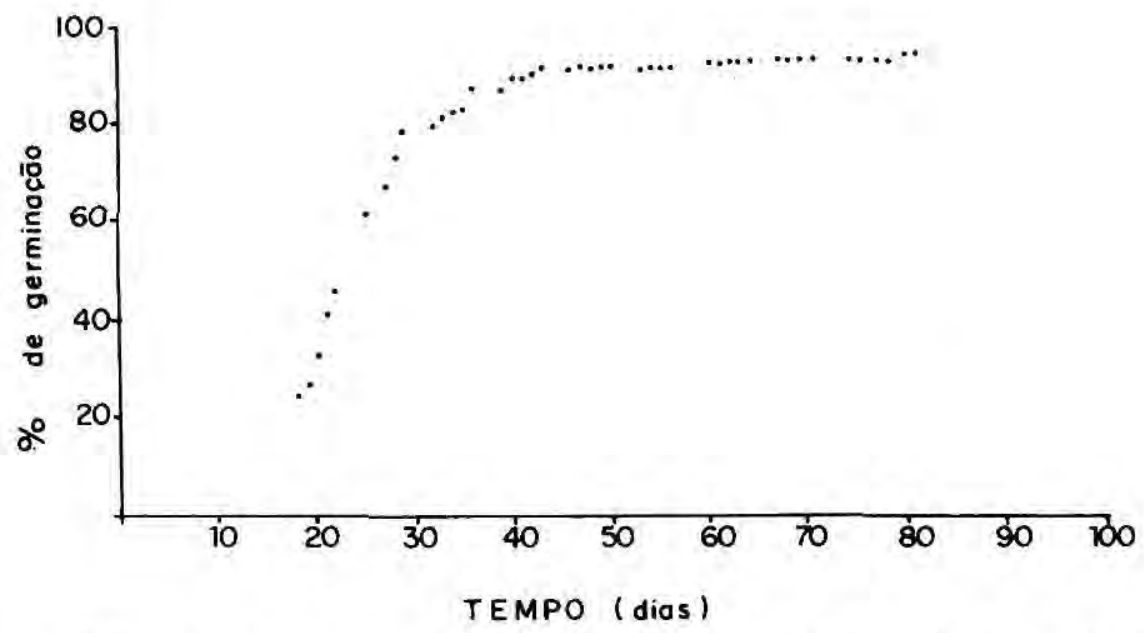

Figura 2. Porcentagem de germinação acumulada de sementes de Swartzia laevicarpa Amshoff (saboarana) em função do tempo (em 100 sementes).

e subterrânea e rigidez do caule da parte aérea, em mudas de 4 meses. (LIMSTRON, 1963). Neste trabalho, As maiores médias de todos os estudou-se o comportamento de todos parâmetros analisados foram obtidas estes parâmetros em 5 diferentes nos substratos: convencional, areia e substratos no viveiro. A Tabela 1 terriço de floresta sem adubo. Estas mostra os resultados obtidos nos médias não diferiram estatisticamente diferentes parâmetros de crescimento entre si. Por outro lado as menores

Tabela 1. Swartzia laevicarpa Amshoff: ("Saboarana"). Medidas em mudas de quatro 4 meses de diferentes parâmetros em cinco substratos.

\begin{tabular}{|c|c|c|c|c|c|}
\hline SUBSTRATOS & AREIA & VÁRZEA & CONVENCIONAL & $\begin{array}{l}\text { TERRIÇO DE } \\
\text { FLORESTA } \\
\text { SEM ADUBO }\end{array}$ & $\begin{array}{l}\text { TERRIÇO DE } \\
\text { FLORESTA } \\
\text { COM ADUBO }\end{array}$ \\
\hline \multicolumn{6}{|l|}{ PARÂMETROS (1) } \\
\hline Altura $(\mathrm{cm})$ & $70,66 \pm 6,13 \mathrm{a}(2)$ & $58,13 \pm 3,25 b$ & $74,00 \pm 6,60 a$ & $67,20 \pm 2,27 a$ & $54,13 \pm 6,21 \mathrm{~b}$ \\
\hline Diâmetro (mm) & $6,78 \pm 1,12 a$ & $4,16 \pm 0,48 c$ & $6,10 \pm 1,10 a$ & $6,70 \pm 0,52 a$ & $5,20 \pm 1,02 b$ \\
\hline $\begin{array}{l}\text { Peso }(\mathrm{g}) \text { da parte } \\
\text { aérea fresca }\end{array}$ & $15,27 \pm 5,69 a$ & $8,32 \pm 0,69 \mathrm{C}$ & $17,20 \pm 4,58 \mathrm{a}$ & $17,87 \pm 2,16 a$ & $13,60 \pm 6,44 b$ \\
\hline $\begin{array}{l}\text { Peso (g) da parte } \\
\text { aérea seca }\end{array}$ & $7,13 \pm 2,45$ & $4,38 \pm 0,63$ & $7,80 \pm 2,75$ & $7,87 \pm 0,62$ & $5,79 \pm 2,10$ \\
\hline
\end{tabular}

(1) Média de cinco plantas.

(2) Média com diferentes letras na mesma linha diferem entre si estatisticamente pelo teste de Tuckey.

(3) As médias de peso seco da planta nāo diferiram estatisticamente. 
médias de todos os parâmetros analisados foram obtidas nos substratos mais férteis: solo de várzea e terriço de floresta com adubação. Estes resultados indicam uma adaptação da "Saboarana" a condições de baixa fertilidade, o que pode ser observado por sua ocorrência em condições naturais - rios de água preta que possuem baixa quantidade de nutrientes.

Em todos os substratos, não houve fase estacionária de crescimento. Porém, observou-se uma tendência geral para diminuir a velocidade de crescimento após um determinado período que variou conforme o substrato (Fig.3). A diminuição na velocidade de crescimento foi mais acentuada no solo de várzea - justamente o substrato de maior fertilidade.

CARNEIRO (1981) afirma que um parâmetro de crescimento não deve ser usado como critério único para classificação de mudas. Contudo, o diâmetro do colo tem sido reconhecido como um dos melhores, se não o melhor dos indicadores de padrão de qualidade. SCHMIDT - VOGT (1966). BACON (1979) e CARNEIRO (1980) apud PARVIAINEN (1981) constataram que existe uma correlação muito forte entre o diâmetro do colo

SUBSTRATOS

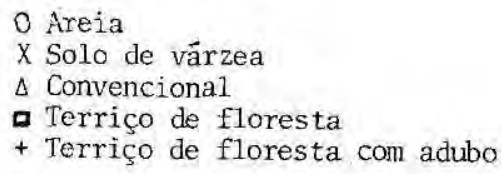

O Areia

$X$ Solo de várzea

$\triangle$ Convencional

- Terriço de floresta

+ Terriço de floresta com adubo

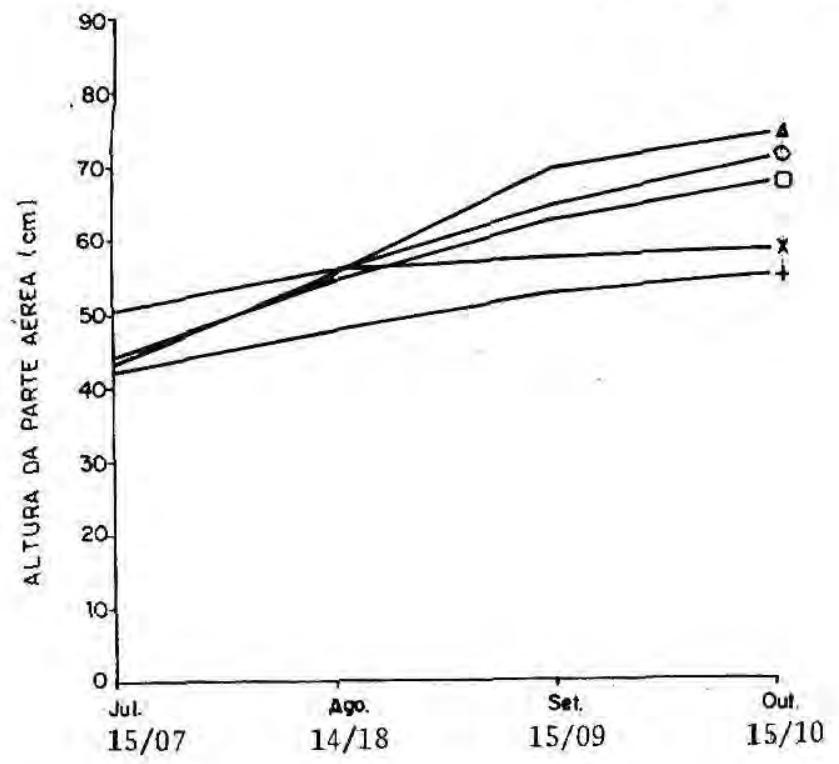

Figura 3. Altura da parte aérea de mudas de Swartzia laevicarpa Amshoff (saboarana) em diferentes substratos em função do tempo (médias de 15 plantas). 
e o valor de reflorestamento de mudas. $\mathrm{O}$ diâmetro do colo pode ter estreita relação, em certas espécies, com a altura e peso da parte aérea, como é o caso da Pseudotsuga meuziiesii (WILSON \& CAMPBEL 1972 apud CARNEIROO, 1981). A correlação entre a altura da planta e o diâmetro do colo em "Saboarana" variou com o substrato (Fig.4). Os maiores coeficientes de correlação foram encontradas em terriço de floresta mais adubo $(0,90)$ e areia $(0,75)$, sendo menores que 0,67 nos demais substratos.

A correlação entre o diâmetro do colo e peso da parte aérea seca (Fig. 5), foi maior que a correlação diâmetro-altura em todos os substratos (exceto areia). Nos substratos terriço de floresta com adubo $(0,96)$ e terriço de floresta sem adubo $(0,97)$, a correlação foi altamente significativa, situando-se acima do nível de $99 \%$. No substrato convencional $(0,79)$ pode ser considerado entre $80-90 \%$ significativo, Considerando que a "Saboarana" é uma espécie madeireira, estes resultados demonstram que o diâmetro do colo é o parâmetro mais adequado para se aferir a qualidade de mudas desta espécie.

A "Saboarana" é uma leguminosa cuja capacidade de nodular, ou seja, de se associar simbioticamente com bactérias fixadoras de nitrogênio foi recentemente descoberta (MAGALHAES, 1989; MOREIRA et al., 1992). A fixação biológica de nitrogênio tem sido explorada economicamente em outras leguminosas nodulíferas, sendo a soja o melhor exemplo: no Sul do país a adubação nitrogenada é substituida totalmente pela inoculação das sementes com estirpes de rizóbio selecionadas. Estudos realizados com

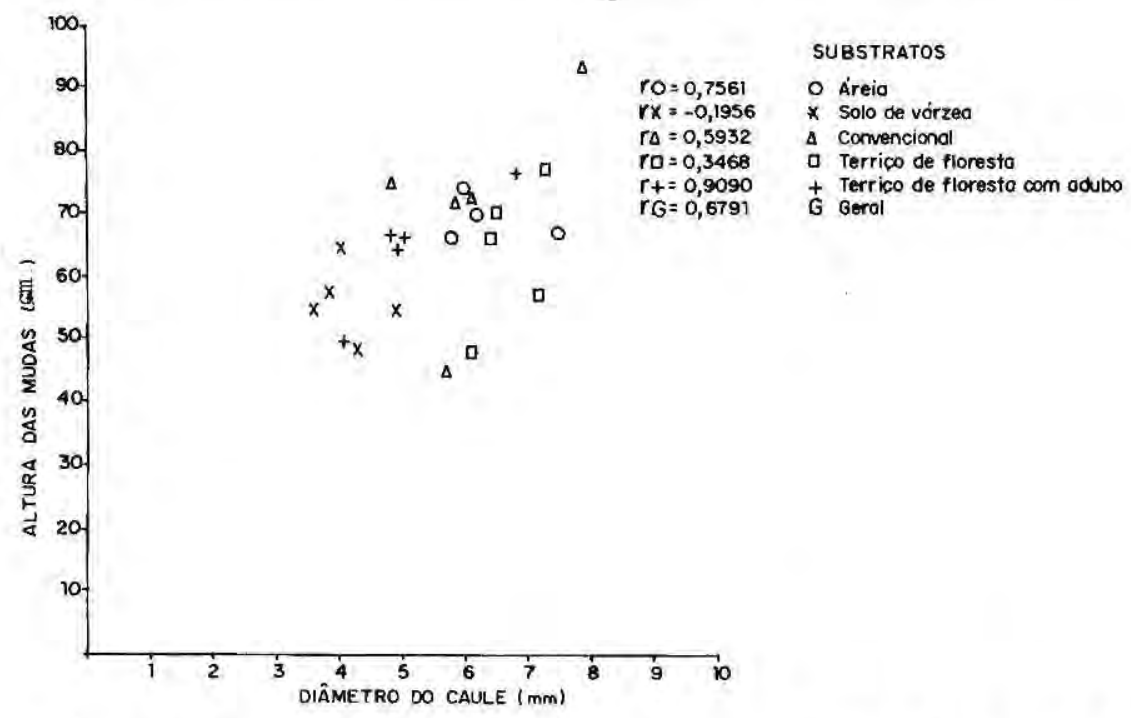

Figura 4. Coeficientes de correlação entre altura e diâmetro do colo de mudas de Swartzia laevicarpa Amshoff (saboarana) em diferentes substratos. 


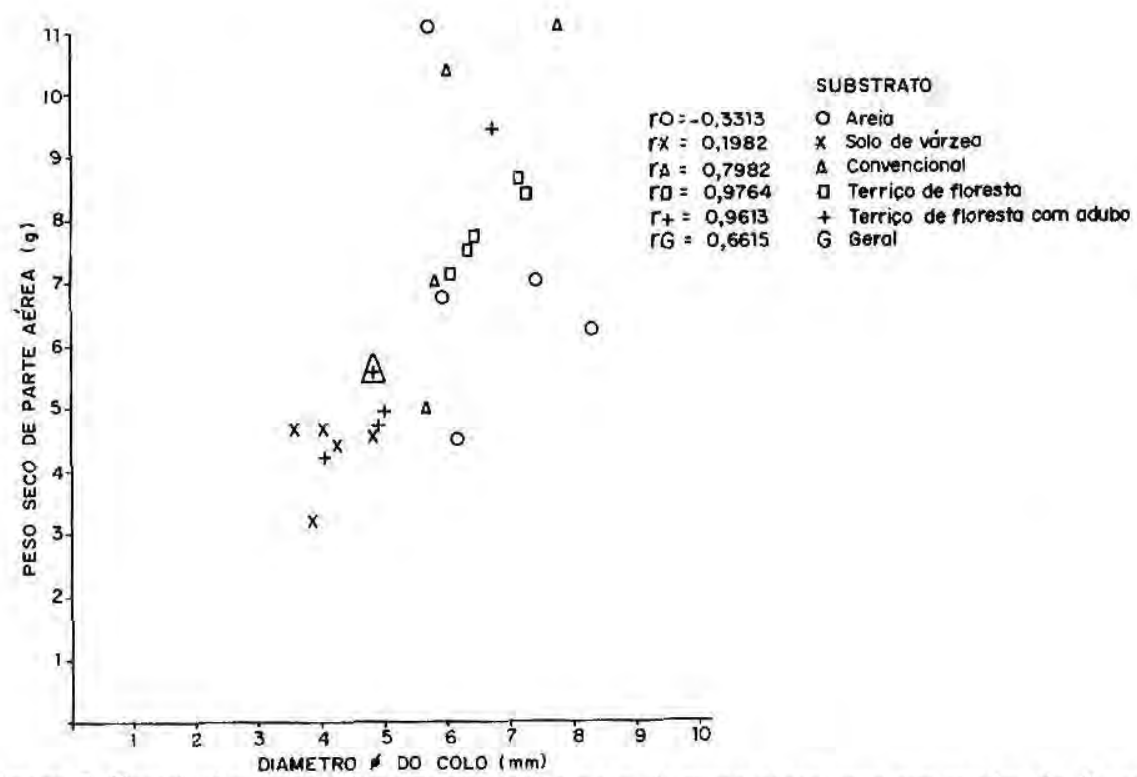

Figura 5. Correlação entre diâmetro do colo e peso da parte aérea seca em mudas de Swartzia laevicarpa Amshoff (Saboarana).

espécies florestais mostram que leguminosas noduladas têm melhor estabelecimento e desenvolvimento de mudas no campo (DOBEREINER, 1967; FARIA et al., 1985) e que a inoculação com estirpes eficientes pode suprir pelo menos parcialmente as necessidades nutricionais de várias espécies com relação ao nitrogênio (FARIA et al., 1984; QUADROS et al., 1986).

Neste trabalho observou-se o comportamento da nodulação de "Saboarana" em diferentes substratos. Destes, apenas o substrato areia foi inoculado com um coquetel de 100 estirpes de rizóbio isoladas de várias espécies florestais porque ainda não existem trabalhos de seleção de estirpes eficientes para esta espécie. Inoculou-se um grande número de estirpes para proporcionar uma população de rizóbio bastante diversificada e consequentemente com maior probabilidade de nodular a espécie. Nos demais substratos, a nodulação foi induzida por estirpes de rizóbio nativas do próprio substrato. $\mathrm{O}$ número de nódulos nos substratos solo de várzea e terriço de floresta com adubo foi muito baixo (Tab. 2), sendo nulo em quase todas as plantas. Em trabalhos anteriores (MAGALHÃES, 1984), várias espécies florestais apresentaram melhor crescimento e nodulação em solo de várzea. Em Latossolo amarelo, na Amazônia, a adição de micronutrientes e calagem favoreceu o crescimento e nodulação da soja (ALFAIA et al., 1988). Neste estudo observou-se que a "Saboarana" tem um comportamento contrário ao destas espécies, não só com relação ao crescimento, mas também com relação a 
Tabela 2. Número de nódulos por planta em mudas de Swartzia laevicarpa Amshoff ("Saboarana") em diferentes substratos em plantas com quatro meses.

\begin{tabular}{|c|c|c|c|c|c|c|c|c|c|c|}
\hline \multirow{4}{*}{$\begin{array}{l}\text { SUBSTRATO } \\
\text { PLANTA }\end{array}$} & \multirow{2}{*}{\multicolumn{2}{|c|}{ AREIA }} & \multirow{2}{*}{\multicolumn{2}{|c|}{ VÁRZEA }} & \multirow{2}{*}{\multicolumn{2}{|c|}{ CONVENCIONAL }} & \multirow{2}{*}{\multicolumn{2}{|c|}{$\begin{array}{l}\text { TERRIÇO DE } \\
\text { FLORESTA } \\
\text { SEM ADUBO }\end{array}$}} & \multirow{2}{*}{\multicolumn{2}{|c|}{$\begin{array}{l}\text { TERRIÇO DE } \\
\text { FLORESTA } \\
\text { COM ADUBO }\end{array}$}} \\
\hline & & & & & & & & & & \\
\hline & \multirow[t]{2}{*}{ № } & \multirow{2}{*}{$\begin{array}{c}\text { Peso } \\
\text { (g) }\end{array}$} & \multirow[t]{2}{*}{$\mathrm{N}^{\mathrm{o}}$} & \multirow{2}{*}{$\begin{array}{l}\text { Peso } \\
\text { (g) }\end{array}$} & \multirow[t]{2}{*}{ № } & \multirow{2}{*}{$\begin{array}{l}\text { Peso } \\
\text { (g) }\end{array}$} & \multirow[t]{2}{*}{ № } & \multirow{2}{*}{$\begin{array}{c}\text { Peso } \\
\text { (g) }\end{array}$} & \multirow[t]{2}{*}{ № } & \multirow{2}{*}{$\begin{array}{c}\text { Peso } \\
\text { (g) }\end{array}$} \\
\hline & & & & & & & & & & \\
\hline 1 & 26 & 0,06 & 14 & 0,04 & 93 & 0,21 & 01 & 0,005 & 00 & 0 \\
\hline 2 & 40 & 0,11 & 00 & 0 & 117 & 0,32 & 02 & 0,01 & 00 & 0 \\
\hline 3 & 37 & 0,07 & 00 & 0 & 33 & 0,09 & 35 & 0,06 & 00 & 0 \\
\hline 4 & 46 & 0,11 & 00 & 0 & 28 & 0,01 & 15 & 0,02 & 11 & 0,01 \\
\hline 5 & 03 & 0,005 & 00 & 0 & 08 & 0,005 & 03 & 0,015 & 00 & 0 \\
\hline Média & \multicolumn{2}{|c|}{$30,4+16,94$} & \multicolumn{2}{|c|}{$2,8+6,26$} & \multicolumn{2}{|c|}{$55,8+46,65$} & \multicolumn{2}{|c|}{$11,2+14,46$} & \multicolumn{2}{|c|}{$2,2+4,91$} \\
\hline
\end{tabular}

nodulação em solo de várzea e solo adubado. O maior número de nódulos ocorreu no substrato convencional (Tab. 2), justamente aquele que favoreceu o melhor crescimento das mudas.

CARNEIRO (1981) assinala que as plantas com maior peso do sistema radicular (proporcional ao da parte aérea), tem maiores chances de sobrevivência após o plantio. A relação entre o peso da raíz e o peso da parte aérea é considerada uma característica segura de qualidade. WILDI et al. (1964) e SCHMIDTVOGT (1966), citados por PARVIAINEN (1981), demonstraram que o peso da raiz da muda repicada deve representar $1 / 3$ a $1 / 4$ do peso da

Tabela 3. Peso da raiz (R) da planta inteira (PI) e relaçao R/PI de Swartzia laevicarpa Amshoff em plantas com quatro meses.

\begin{tabular}{|c|c|c|c|c|c|}
\hline SUBSTRATOS & AREIA & VARZEA & CONVENCIONAL & $\begin{array}{l}\text { TERRIÇO DE } \\
\text { FLORESTA } \\
\text { SEM ADUBO }\end{array}$ & $\begin{array}{l}\text { TERRIÇO DE } \\
\text { FLORESTA } \\
\text { COM ADUBO }\end{array}$ \\
\hline \multicolumn{6}{|c|}{ MATÉRIA VERDE } \\
\hline Peso da raiz $(\mathrm{g})$ & 4,59 & 1,74 & 3,55 & 3,58 & 1,82 \\
\hline Peso da muda inteira (g) & 19,86 & 10,06 & 20,75 & 21,75 & 15,42 \\
\hline $\begin{array}{l}\text { Relação peso raiz/peso } \\
\text { parte aérea }\end{array}$ & 0,23 & 0,17 & 0,17 & 0,17 & 0,11 \\
\hline \multicolumn{6}{|c|}{ MATÉRIA SECA } \\
\hline Peso da raiz (g) & 1,90 & 0,73 & 2,00 & 2,09 & 0,85 \\
\hline Peso da muda inteira ( $\mathrm{g}$ ) & 9,03 & 5,11 & 9,80 & 9,96 & 6,64 \\
\hline $\begin{array}{l}\text { Relação peso raiz/peso } \\
\text { parte aérea }\end{array}$ & 0,21 & 0,14 & 0,20 & 0,20 & 0,12 \\
\hline
\end{tabular}

(1) Média de cinco plantas 
muda inteira. Em saboarana, os maiores índices peso raiz/peso da muda inteira foram obtidos justamente nos substratos que apresentaram maior crescimento: Areia, Convencional e Terriço de floresta sem adubo (Tab. 3). No entanto em nenhum deles foi atingido o coeficiente mínimo de padrão de qualidade 0,25 - citado por SCHIMIDT - VOGT (1966) para outras espécies. Seria interessante verificar em estudo posterior se esses índices são adequados para a "Saboarana" ou se ainda podem ser incrementados através de técnicas de manejo.

Avaliações da rigidez da haste demonstraram que nenhuma das 75 plantas do viveiro apresentou tombamento da parte aérea e as hastes se apresentavam com aspecto lenhoso.

\section{CONCLUSÕES}

\section{As sementes de "Saboarana"} são poliembriônicas, têm polimorfismo acentuado e germinação do tipo hipogeal.

2. Sementes de "Saboarana" coletadas no mês de maio apresentam alta porcentagem de germinação (94\%), aos oito dias após a coleta.

3. O crescimento de mudas de "Saboarana" é melhor em substratos de baixa fertilidade, como: mistura de argila com areia na proporção $3: 2$; areia lavada mais adubação mineral e inóculo de rizóbio e terriço de floresta sem adubo mineral.

4. Plantas inoculadas com mistura de estirpes de Rhizobium e Bradyrhizobium e não inoculadas, mas que se desenvolveram em sistema convencional de substrato (mistura argila e areia, 3:2) para produção de mudas, apresentaram nodulação abundante.

\section{AGRADECIMENTOS}

A FINEP pelo apoio financeiro através do projeto 54.84 .0294 .00 . Ao CNPq pela bolsa de pesquisa concedido ao $2^{\circ}$ autor. Este trabalho foi apresentado como monografia do $1^{\circ}$ autor sob orientação dos co-autores para obtenção do grau de Tecnólogo Florestal da UTAM, AM.

\section{Bibliografia Citada}

ALFAIA, S.S.; MAGALHÃES, F.M.M; YUYAMA, K.; MURAOKA, T. 1988.Efeito da aplicação de calcário e micronutrientes na cultura da soja em Latossolo amarelo da Amazônia Central. Acta Amazônica 18(3-4):13-25.

BACON, C.J. 1979 a. - Seedling morphology as an indicator of planting stock quality in conifers. 29 s. Esit, I UFRO-Worshop "Techniques for Evaluating Planting Stock Quality" New Zealand, August 1979. Apud: PARVIAINEN. J. Qualidade e Avaliação da Qualidade de Mudas Florestais, $I_{-}^{\circ}$ Seminánio de sementes e viveiros flonestais. Curitiba, 4 a 8 de maio 1981. Fund. Pesq. Flores, Paraná, Vol. II.

CARNEIRO, J.G. A. 1980. - Untersuchungen zu Fragen der morphologischen merkmale und des Wasserhaushaltes junger Koniferenpflanzen, 236 s. Diss. Waldbau-Institut. Albert-Ludwigs-Universitat. Freiburg i. Dr. Apud: PARVIAINEN, J., Qualidade e Avaliação da Qualidade de Mudas Florestais, IN. $I^{\circ}$ Seminário de sementes e viveiros florestais. Curitiba, 4 a 8 de maio 1981. Fund. Pesq. Flores, Paraná. Vol. II.

CARNEIRO, J.G.A. 1981 - Influência do sítio sobre o desenvolvimento dos parâmetros 
morfológicos indicadores da qualidade de mudas, In: $I^{o}$ Seminário de sementes e viveiros florestais. Curitiba, 4 a 8 de maio de 1981. Fund. Pesq. Flores, Paraná. Vol. II.

DOBEREINER, J, 1967. Efeito da inoculação de sementeiras de sabiá (Mimosa caesalpinifolia) no estabelecimento e desenvolvimento de mudas no campo. Pesquisa Agropecuária Brasileira, 2:301- 305 .

DUCKE, A. 1949 - Notas sobre a Flora Neotrópica - II. As Leguminosas da Amazônia Brasileira. (2a. ed.). Ed. Tec. AN 18. 248p.

FARIA, S.M.; MOREIRA, V.C.G.; FRANCO, A.A. 1984, Selection of Rhizobium spp for forest legumes, Pesquisa Agropecuária Brasileira, 19(s/ng): 175-179.

FARIA, S.M.; JESUS, R.M.; FRANCO, A.A. 1985. Field stablishment of nodulated Leucaena leucocephalla $\mathrm{k} 72$ Leucaena Research Reports 6:14-16.

LOUREIRO, A.A.; RODRIGUES, W.A. 1975. Estudo anatômico da madeira do gênero Swartzia (Leguminosae) da Amazônia - I, Acta Amazônica, 5(1):79-86.

LOUREIRO, A.A.; SILVA, M.F; ALENCAR, J.C. - Essências madeireiras da Amazônia. Manaus-AM, INPA, Vol. II. 1979.

LIMSTROM, G.A., 1963. - Forest planting practice in the central states. US Forest Serv, Agric. Handb. № 247.

MAGALHÃES, F.M.M. 1984. Nodulação e crescimento de leguminosas florestais em condições de viveiro. 1. Nodulação e crescimento de 33 espécies de leguminosas florestais nativas e exóticas da região de Manaus-AM. Resumos da XII Reunião Latino-Americana sobre Rhizobium. Campinas, 21-26 de outubro de 1984. p. 179.

MAGALHAES, F.M.M. 1989. Relatório técnico final do projeto "Levantamento da capacidade de nodulação elou fixação de nitrogênio de espécies florestais da região amazônica". Convênio INPAVCODEAMA FINEP ref: $54.84 .0294 .00,54 \mathrm{p}$.

MOREIRA, F.M.S.; SILVA, M.F; FARIA, S.M, 1992. Occurrence of nodulation in legume species in the Amazon region of Brazil. New Phytologist, 121:563-570.

POLHILL, R.M.; RAVEN, P.H.; STIRTON C. H. Evolution and Systematics of the Leguminosae. Evolution and Systematics of the Leguminosae. In: POLHILL, R.M. \& RAVEN, P.H. (eds). Advances in legume systematics. Part 1 Kew: Royal Botanic Gardens, 1981, p. 1-26.

RIBEIRO Jr., W.Q; FRANCO, A.A.; LOPES, E.S. 1986. Eficiência e competitividade de estirpes de Bradyrhizobium spp para Enterolobium contortsiliquum, em latossolo ácido. Revista Brasileira de Ciência do Solo, 10:219-255.

SCHMIFDT-VOGT, II. 1966, Wachstum und Qualitat von Forstpflanzen. 2. erw. Auflage von: Die Gutebeurteilung von Forstpflanzen, Munique-Basel - Viena. Apud: CARNEIRO, J. G. A, Influência do sítio sobre o desenvolvimento dos parâmetros morfológicos indicadores da qualidade de mudas, In: $1^{\circ}$ Seminário de sementes $e$ viveins florestais, Curitiba, 4 a 8 de maio de 1981. Fund. Pesq. Flores. Paraná. Vol. II.

WILSON, B.C.; CAMPBEL, R.K. 1972. Seedbed Jensity influences height, diameter, and dry weight of $3 / 0$ douglas-fir. Tree Planters notes Vol. 23. N ${ }^{\circ}$ 2. Apud: CARNEIRO, J.G.A., Influência do sítio sobre o desenvolvimento dos parâmetros morfológicos indicadores da qualidade de mudas, In: $1^{\circ}$ Seminário de sementes $e$ viveiros florestais. Curitiba, 4 a 8 de maio de 1981. Fund. Pesq. Flores. Paraná, Vol. II.

WILDE, S.A., VOLGT, C.K. \& IYER, J.G. 1964, Soil and plant analysis for the tree culture. 3rd Edit. 209 s. New Delhi.Oxford Publishing House. 